\title{
Transition Zone Prostate Specific Antigen Density Improves Prostate Cancer Detection in Iranian Men
}

\author{
Mohammadreza Nowroozi ${ }^{1}$; Mohsen Ayati ${ }^{1}$; Hassan Jamshidian ${ }^{1}$; Amir Arbab ${ }^{1}$; Hamidreza \\ Ghorbani $^{1{ }^{1,}}$; Erfan Amini ${ }^{1}$; Hassan Hakima ${ }^{2}$; Sohrab Salehi ${ }^{3}$; Alireza Ghadian ${ }^{4}$ \\ ${ }^{1}$ Uro-Oncology Research Center, Tehran University of Medical Sciences, Tehran, IR Iran \\ ${ }_{3}^{2}$ Farhangian University, Qazvin, IR Iran \\ ${ }^{3}$ Department of Urology, Qazvin University of Medical Sciences, Qazvin, IR Iran \\ ${ }^{4}$ Nephrology and Urology Research Center, Baqiyatallah University of Medical Sciences, Tehran, IR Iran \\ ${ }^{*}$ Corresponding author: Hamidreza Ghorbani, Uro-Oncology Research Center, Tehran University of Medical Sciences, Tehran, IR Iran. Tel/Fax: +98-2166903063, E-mail: \\ ghorbanihamidreza@yahoo.com
}

Received: January 11, 2015; Accepted: February 1, 2015

\begin{abstract}
Background: Prostate specific antigen (PSA) as a tumor marker has extensively changed the diagnosis of prostate cancer (PCa). With the advent of PSA, the majority of patients are diagnosed with nonpalpable early stage PCa. However, PSA lacks specificity and many patients undergo unnecessary biopsies due to an elevated serum PSA level.

Objectives: This study aimed to assess the sensitivity and specificity of transition zone PSA density (TZPSAD) in detection of PCa.

Patients and Methods: This study was performed on 1712 men underwent trans-rectal ultrasound guided prostate biopsy in our institution between March 2008 and March 2013. A total of 1120 men with PSA < 20 ng/mL and normal digital rectal exam were selected for evaluation. Transition zone PSA density was calculated in all patients and the receiver operating characteristic (ROC) curve was used to analyze the accuracy of TZPSAD for the diagnosis of PCa.

Results: Among 1120 men who were eligible for enrolment, prostate cancer was detected in 265 patients. Mean serum PSA levels were 9.7 $\pm 4.3 \mathrm{ng} / \mathrm{mL}$ and $8.5 \pm 3.7 \mathrm{ng} / \mathrm{mL}$ in patients with and without $\mathrm{PCa}$, respectively $(\mathrm{P}<0.001)$. Mean value for TZPSAD was $1.18 \pm 1.19 \mathrm{ng} / \mathrm{mL} / \mathrm{mL}$ in patients with $\mathrm{PCa}$, whereas it was $0.55 \pm 0.84 \mathrm{ng} / \mathrm{mL}$ in men without cancer $(\mathrm{P}<0.001)$. Optimal cut-off value for TZPSAD was $0.32 \mathrm{ng} / \mathrm{mL}$. At this cut-off value, the sensitivity and specificity values for TZPSAD were $85 \%$ and $45 \%$, respectively. Applying the TZPSAD for PCa screening decreased $50 \%$ of unnecessary biopsies.

Conclusions: Using TZPSAD as an adjunct to PSA may improve the specificity of PSA in the diagnosis of PCa and decrease the number of unnecessary prostatic biopsies in Iranian men with serum PSA level $<20 \mathrm{ng} / \mathrm{mL}$.
\end{abstract}

Keywords: Prostatic Neoplasms; Prostate-Specific Antigen; ROC Curve; Sensitivity and Specificity

\section{Background}

Prostate cancer (PCa) is one of the most common cancers in the United States and most Western countries (1, 2). Prostate specific antigen (PSA) test is widely used for PCa screening in men. Considerable overlap exists between PCa and benign prostatic hyperplasia (BPH)among patients with serum PSA level $<10 \mathrm{ng} / \mathrm{mL}$ (1-4). Extensive efforts have been made to increase PSA specificity in detecting PCa. Benson et al. introduced PSA density (PSAD) and transition-zone PSA density (TZPSAD) as parameters that improve detection of PCa (5). However, some studies have questioned diagnostic capability of PSAD (6). Hyperplasia of the transition zone almost exclusively results in $\mathrm{BPH}$ (7). Kalish et al. reported TZPSAD as a parameter, which increases PCa detection among patients with mildly elevated serum PSA(PSA between 4-10 ng/mL) (8). Due to variation of PCa prevalence and incidence in different regions (3), and importance of ethnicity in PCa pathogenesis, we conducted this study to assess the util- ity of TZPSAD among Iranian patients. Serum PSA level seems to be higher in Iranian patients and the PSA cutoff value of $4 \mathrm{ng} / \mathrm{dL}$ may be associated with substantial number of unnecessary biopsies (9). Therefore, finding a more specific PSA-related biomarker and determining an optimal cut-off value in Iranian patients are of utmost importance.

\section{Objectives}

This study aimed to assess the sensitivity and specificity of transition-zone PSA density (TZPSAD) in detection of PCa.

\section{Patients and Methods}

\subsection{Patients}

Between March 2008 and March 2013, 1712 patients un-

Copyright ( ) 2015, Nephrology and Urology Research Center. This is an open-access article distributed under the terms of the Creative Commons Attribution-NonCommercial 4.0 International License (http://creativecommons.org/licenses/by-nc/4.0/) which permits copy and redistribute the material just in noncommercial usages, provided the original work is properly cited 
derwent trans-rectal ultrasound (TRUS) guided prostate biopsy in our institution. Patients younger than 40 years were excluded from the study. Other exclusion criteria were abnormal rectal exam findings, serum PSA level $>$ $20 \mathrm{ng} / \mathrm{mL}$, genitourinary manipulation and intervention (within one month of biopsy) and the use of an indwelling Foley catheter. A total of 1120 patients were eligible and included for the statistical analysis. The institutional review board approved the study.

\subsection{Ultrasonography and Biopsy}

Trans-rectal ultrasound was performed using a linear array probe. Interrogation of the prostate parenchyma was performed in both transverse and sagittal planes. Anteroposterior and transverse diameters of prostate and transition zone were recorded. Ultrasonography in sagittal plane was also applied to determine a longitudinal diameter of the prostate and transition zone. Prostate volume and transition-zone volume were calculated using ellipsoid volume formula (width $\times$ length $\times$ height $\times$ $0.52)$. The transition-zone PSA density was calculated as PSA (ng/mL) divided by transition-zone volume $(\mathrm{mL})$. Biopsy procedure from prostate was consisted of 12 cores. Additional biopsies were also obtained from hypo-echoic regions detected by TRUS.

\subsection{Statistical Analysis}

Receiver operating characteristic curve was used to evaluate the diagnostic accuracy of TZPSAD in detecting PCa.

\section{Results}

A total of 1349 men with mean age of $65.7 \pm 8.4$ years (age range, 43 - 96 years) were included. Prostate cancer was detected in 340 (25.2\%) men. Mean serum PSA level was $8.9 \pm 4.1 \mathrm{ng} / \mathrm{mL}$ in the study population and was significantly higher among patients with PCa $(10.0 \pm 4.4 \mathrm{ng} / \mathrm{mL}$ vs. $8.6 \pm 3.9 \mathrm{ng} / \mathrm{mL}$ in men with and without PCa, respectively; $\mathrm{P}<0.001)$.

Mean TZPSAD value was $0.70 \pm 0.97 \mathrm{ng} / \mathrm{mL} / \mathrm{mL}$ in study population (range from 0.03 to $12.73 \mathrm{ng} / \mathrm{mL} / \mathrm{mL}$ ). We noted a significantly higher TZPSAD among patients with PCa $(1.18 \pm 1.19$ vs. $0.55 \pm 0.84 \mathrm{ng} / \mathrm{mL} / \mathrm{mL} ; \mathrm{P}<0.001)$. Table 1 compares various characteristics between patients with and without PCa.

The areas under the curves for PSA, PSAD and TZPSAD were $0.585,0.749$ and 0.766 , respectively (Figure 1). Optimal cut-off values for PSA, PSAD and TZPSAD were $5.6 \mathrm{ng} /$ $\mathrm{mL}, 0.14$ and $0.32 \mathrm{ng} / \mathrm{mL} / \mathrm{mL}$, respectively. At these cut-off values, sensitivity and specificity were $85 \%$ and $24 \%$ for PSA, $85 \%$ and $40 \%$ for PSAD and $85 \%$ and $45 \%$ for TZPSAD, respectively. Applying TZPSAD for PCa screening reduced $50 \%$ of unnecessary biopsies.

\section{Discussion}

Serum PSA is an invaluable biomarker for detection of PCa. Patients with elevated serum PSA levels should undergo TRUS guided prostatic biopsy. Prostate specific antigen is a tissue specific marker. However, it is not specific for PCa. Serum PSA level increases by disruption of cell architecture within the gland which occurs as a consequence of different prostatic disorders, inflammation or lower urinary tract intervention. Moreover, benign prostatic hyperplasia may increase serum PSA level, especially when it is associated with prostatitis. Therefore, PSA lacks specificity for PCa detection and many patients with elevated PSA undergo unnecessary prostatic biopsies. Applying PSA related parameters (i.e. PSAD, PSA velocity, etc.) have been postulated to increase specificity and decrease the number of unnecessary biopsies. In the present study, we noted that applying TZPSAD as a marker for PCa detection is associated with significantly higher specificity and decreases the number of unnecessary biopsies. Since transition-zone enlargement occurs mainly in BPH patients, TZPSAD is hypothesized to more accurately discriminate between BPH and PCa. In 1994, Kalish et al. reported that TZPSAD at cut-off value of $0.45 \mathrm{ng} / \mathrm{mL} /$ $\mathrm{mL}$ is more specific than PSA and PSAD in detecting PCa among patients with intermediate PSA levels of 4-10 $\mathrm{ng} /$ $\mathrm{mL}$ (8). Similarly Sung et al. reported TZPSAD at cut-off

Table 1. Comparing Various Clinical Variables Between Patients With and Without Prostate Cancer ${ }^{\mathrm{a}, \mathrm{b}}$

\begin{tabular}{lccc}
\hline & Patients With Prostate Cancer & Patients Without Prostate Cancer & P Value \\
\hline Age, $\mathbf{y}$ & $68.4 \pm 8.5$ & $64.7 \pm 8.1$ & $<0.001$ \\
BMI, $\mathbf{~ k g / m ~}$ & $26.5 \pm 10.3$ & $24.2 \pm 3.2$ & 0.147 \\
\hline Prostate Volume, ng/mL & $35.7 \pm 18.0$ & $53.3 \pm 24.4$ & $<0.001$ \\
Transition Zone Volume, ng/mL & $14.0 \pm 11.1$ & $24.8 \pm 15.0$ & $<0.001$ \\
PSA, ng/mL & $10.0 \pm 4.4$ & $8.6 \pm 3.9$ & $<0.001$ \\
PSA Density, ng/mL & $0.34 \pm 0.23$ & $0.20 \pm 0.33$ & $<0.001$ \\
TransitionZone PSADensity,ng/mL & $1.18 \pm 1.19$ & $0.55 \pm 0.84$ & $<0.001$ \\
\hline
\end{tabular}

a Abbreviations: BMI, Body Mass Index; PSA, Prostate Specific Antigen.

$\mathrm{b}$ Data are presented as Mean \pm SD. 
Nowroozi Met al.

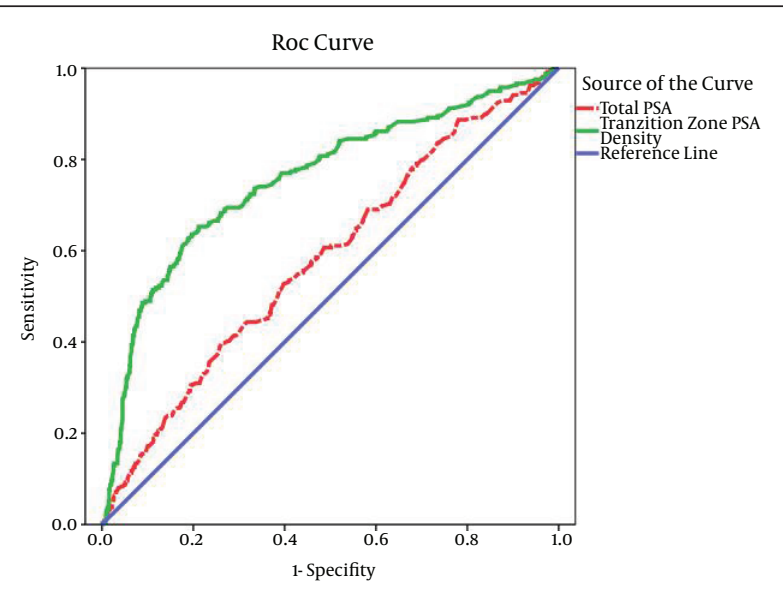

Figure 1. ROC Curve Analysis for Total PSA and PSA Transition Zone Density in the Diagnosis of Prostate Cancer

value of $0.35 \mathrm{ng} / \mathrm{mL} / \mathrm{mL}$ as an specific marker in PCa diagnosis (10). In the present study, we also revealed that at cut-off value of $0.32 \mathrm{ng} / \mathrm{mL} / \mathrm{mL}$, TZPSAD has significantly higher specificity compared to PSA. Although PSAD was more specific compared to PSA, it was not as specific as TZPSAD in our study. Accuracy of PSAD has been evaluated in several reports. Benson et al. first recommended applying PSAD as a marker for distinguishing PCa from the benign causes of PSA elevation (5). Lam et al. showed that PSAD at cut-off value of $0.15 \mathrm{ng} / \mathrm{mL} / \mathrm{mL}$ spread $50 \%$ of men from undergoing unnecessary biopsies (11). In addition, some investigators have shown that PSAD is more specific compared to free to total PSA ratio especially when serum PSA level is at lower range (12-14). In our study, TZPSAD was found to be even more specific compared to PSAD and spread more patients from undergoing unnecessary biopsies.

Prostate specific antigen is not a good predictor for PCa diagnosis. Using TZPSAD can improve the efficiency of PSA in PCa diagnosis and decrease unnecessary biopsies. Applying TZPSAD for PCa screening can reduce 50\% of unnecessary biopsies in Iranian men.

\section{References}

1. Matsuda T, Saika K. Comparison of time trends in prostate cancer incidence (1973-2002) in Asia, from cancer incidence in five continents, Vols IV-IX.Jpn J Clin Oncol. 2009;39(7):468-9.

2. Chen CS, Wang SS, Li JR, Cheng CL, Yang CR, Chen WM, et al. PSA density as a better predictor of prostate cancer than percent-free PSA in a repeat biopsy. J Chin Med Assoc. 2011;74(12):552-5.

3. Matsuda T, Saika K. Comparison of time trends in prostate cancer incidence (1973 1997) in East Asia, Europe and USA, from Cancer Incidence in Five Continents Vols IV VIII. Jpn J Clin Oncol. 2007;37(7):556-7.

4. Oesterling JE. Prostate specific antigen: a critical assessment of the most useful tumor marker for adenocarcinoma of the prostate. J Urol.1991;145(5):907-23.

5. Benson MC, Whang IS, Olsson CA, McMahon DJ, Cooner WH. The use of prostate specific antigen density to enhance the predictive value of intermediate levels of serum prostate specific antigen. J Urol. 1992;147(3 Pt 2):817-21.

6. Mettlin C, Littrup PJ, Kane RA, Murphy GP, Lee F, Chesley A, et al. Relative sensitivity and specificity of serum prostate specific antigen (PSA) level compared with age-referenced PSA, PSA density, and PSA change. Data from the American Cancer Society National Prostate Cancer Detection Project. Cancer. 1994;74(5):1615-20.

7. Hammerer PG, McNeal JE, Stamey TA. Correlation between serum prostate specific antigen levels and the volume of the individual glandular zones of the human prostate. J Urol.1995;153(1):111-4.

8. Kalish J, Cooner WH, Graham SD Jr. Serum PSA adjusted for volume of transition zone (PSAT) is more accurate than PSA adjusted for total gland volume (PSAD) in detecting adenocarcinoma of the prostate. Urology. 1994;43(5):601-6.

9. Dadkhah F, Safarinejad MR, Amini E, Lashay AR, Baghayee A. Utility of prostate specific antigen density and free to total prostate specific antigen ratio for detecting prostate cancer in Iranian men: a prospective study of 187 cases. Curr Urol. 2010;4(1):1-5.

10. Sung DJ, Cho SB, Kim YH, Oh YW, Lee NJ, Kim JH, et al. Comparison of prostate-specific antigen adjusted for transition zone volume versus prostate-specific antigen density in predicting prostate cancer by transrectal ultrasonography. I Ultrasound Med. 2004;23(5):615-22.

11. Lam JS, Cheung YK, Benson MC, Goluboff ET. Comparison of the predictive accuracy of serum prostate specific antigen levels and prostate specific antigen density in the detection of prostate cancer in Hispanic-American and white men. J Urol. 2003;170(2 Pt1):451-6.

12. Zheng XY, Xie LP, Wang YY, Ding W, Yang K, Shen HF, et al. The use of prostate specific antigen (PSA) density in detecting prostate cancer in Chinese men with PSA levels of 4-10 ng/mL.J Cancer Res Clin Oncol. 2008;134(11):1207-10.

13. Stephan C, Stroebel G, Heinau M, Lenz A, Roemer A, Lein M, et al. The ratio of prostate-specific antigen (PSA) to prostate volume (PSA density) as a parameter to improve the detection of prostate carcinoma in PSA values in the range of $<4 \mathrm{ng} / \mathrm{mL}$. Cancer. 2005;104(5):993-1003.

14. Aslan G, Irer B, Kefi A, Celebi I, Yorukoglu K, Esen A. The value of PSA, free-to-total PSA ratio and PSA density in the prediction of pathologic stage for clinically localized prostate cancer. Int Urol Nephrol. 2005;37(3):511-4. 